\title{
Organizational Contact
}

National Cancer Institute

\section{Source}

National Cancer Institute. Organizational Contact. NCI Thesaurus. Code C93361.

A person who provides or receives information on behalf of an org anization. 